\title{
Macro- and micronutrient intakes among severely malnourished under-five children during the economic crisis in Yogyakarta
}

\author{
Endy P Prawirohartono, MD; Atiek Werdiningsih, MD
}

\begin{abstract}
Objective To evaluate macro and micronutrient intakes among under five-year children with severe malnutrition during the period of economic crisis.

Methods We conducted a longitudinal study from August until November 2000 in Bantul and Sleman districts, Yogyakarta Special Territory of Indonesia. Two-weekly home visits were performed to collect data about food intakes.

Results Of 46 children, 26 experienced an improvement in nutritional status, whereas 20 children did not. The median intakes of macro and 8micronutrients were lower than the Recommended Daily Allowances (RDA), ranged from $22 \%$ (vitamin C) to $69 \%$ (phosphorus), except for vitamin A (406\%). The median intakes of protein, vitamin $\mathrm{A}$, thiamin, vitamin $\mathrm{C}$, calcium, iron and phosphorus were higher in severely malnourished children who experienced improvement in nutritional status compared to children who did not, and in breastfed compared to non-breastfed, but Mann Whitney U-test was not able to detect significant differences $(p>0.05)$. Stratification using age group showed that calories and thiamin intakes of older children ( 348 months) were lower than those of younger children (Kruskal Wallis tests $p=0.016$ and 0.022 respectively).

Conclusions The macro and micronutrients intakes of severely malnourished under five-year children were lower than RDA, except for vitamin A. There were differences in nutrient intakes according to the improvement in nutritional status and age group [Paediatr Indones 2003;43:186-191].
\end{abstract}

Keywords: macronutrients, micronutrients, severe malnutrition, economy crisis

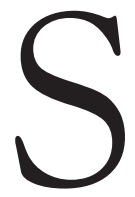

ince the middle of 1997, the national crisis impacted multidimensional aspects. Indonesia, which for decades had enjoyed a robust economic growth suddenly plunged itself into a deep economic crisis, which washed away almost all development achievement that the country had gained so far. ${ }^{1}$ Because of the economic crisis, food availability at the household levels was often in short supply. Based on a food consumption survey from 1995 to 1998 (PKG or 'Pemantauan Konsumsi Gizi'), in general, the crisis changed the mean intake of energy per capita per day as well as the mean intake of protein per capita per day. The mean intakes became inadequate if family size was more than 6 people. The crisis extremely influenced families with 8 or more people live at the household. ${ }^{2}$ Besides economic sectors, the crisis also influenced the health status and worsened the nutritional status of children. According to data from the National Social and Economic Survey (SUSENAS), nutritional deficiency among under fiveyear children (less than $-2 \mathrm{SD}$ of weight for age using WHO-NCHS standard) dropped from 37.5\% in 1989 to $29.5 \%$ in 1998 , to $26.4 \%$ in 1999 , and to $17.13 \%$ in 2000. However, in the age group of 6 to 23 month-old, the prevalence of poor nutrition and malnutrition (less than -3 SD of weight for age using WHO-NCHS

From the Department of Child Health, Medical School, Gadjah Mada University (EPP); Ministry of Health Yogyakarta Special Territory Office (AW).

Reprint requests to: Endy P Prawirohartono, MD, Division of Pediatric Nutrition and Metabolic Disease, Department of Child Health, Sardjito Hospital, Yogyakarta, Indonesia. Tel. 62-274-561616, Fax. 62-274-583745, email: eprawirohartono@yahoo.com 
Endy P Prawirohartono et al: Nutrient intakes in malnourished children during the economic crisis

standard) rose prior to and during the crisis. Children living in rural areas suffered more than those in urban areas, where the prevalence of moderate and severe malnutrition among under five-year children was higher in the rural areas rather than that of the urban areas. Toward the end of 1999, approximately 25,000 children from all Indonesia were reported to experience marasmus, kwashiorkor, and marasmic-kwashiorkor. ${ }^{3}$

One of government policy to ensure the national food security was protecting the poor through the 'Social Safety Net' or JPS ('Jaring Pengaman Sosial'). There were three main nutrition activities being implemented as parts of the Social Safety Net i.e., provision of supplementary feeding to children 0-24 months of age and anemic mothers, revitalizing the 'posyandu' (village nutrition center), and revitalizing the Nutrition Surveillance System. ${ }^{4}$

In Yogyakarta Special Territory, the prevalence of malnutrition in 1999 was $22.73 \%$, and $3.28 \%$ of them were under five-year children with moderate and severe malnutrition. ${ }^{5}$ Based on a preliminary survey conducted in May 2000, the total amounts of under fiveyear children with severe malnutrition (weight for age below $60 \%$ of median standard of WHO-NCHS) in Sleman and Bantul districts were 24 and 28 children respectively. In the middle of the year of 2000 , supplementary feeding packets from the Government stopped. A subsequent question was how the poor fulfill the requirement of food for their children in this situation and what happened with the nutritional status of the children after the absent of food supplementation from the Government. The aim of this study was to evaluate the micro and macronutrient intakes among severely malnourished under-five/year-old children during the economic crisis in Yogyakarta.

\section{Methods}

We conducted an observational study using a longitudinal study design during a 3 -month period, from August through November 2000 in Bantul and Sleman districts of Yogyakarta Special Territory Indonesia. The two districts were chosen purposively based on the accessibility. This study was a part of a collaborative study consisted of three topics: 'Factors associated with severe malnutrition among under five-year children in Yogyakarta during the economic crisis', 'Factors influencing the improvement of nutritional status of under five-year old children in Sleman and Bantul districts, Yogyakarta', and 'Macro and micronutrient intakes among severely malnourished under five-year children in Yogyakarta during the economic crisis'.

The study population was under-five children with severe malnutrition from the study sites. Sample size was 47 children, calculated using values of $z \alpha=$ $1.960, z \beta=0.842$, Po $=0.5$ (the proportion of improvement possibility in nutritional status at the beginning of the study), and $\mathrm{Pa}=0.7$ (the proportion of improvement possibility in nutritional status at the end of the study). ${ }^{6}$ Severe malnutrition was identified using weight for age $<60 \%$ of median of WHONCHS standard. Study sample was all severely malnourished children from the study sites. According to preliminary survey, there were 52 severely malnourished children in the study sites, but only 46 children were enrolled because of several reasons. Five children were excluded; two because of misdiagnosis, 1 child had a congenital anomaly, and the other two due to technical difficulties.

At the beginning of the study, we collected basic data including demography, weight, and nutritional status of the children. Two-week interval home visits were performed to collect data about food intakes; in the collaborative study, data about diseases and data of control group were also collected. At the end of the study, weight and nutritional status of the children were measured. Data of food intakes were collected using a food record method. Parents or other family members were trained to record food consumed using a special form. Therefore, during the 3 -month period, there were 6 food records available for analysis for each child. Children were weighed using Kubota Baby Scale or Kubota Bath Scale to the nearest $0.05 \mathrm{~kg}$ and $0.5 \mathrm{~kg}$ respectively. A dietitian converted food intakes from household measures to gram, and then Food Processor-2 calculated the compositions of the food consumed by the children.

Data entry and analysis were done using SPSS for Windows version 10.0. Parametric analysis of Mann Whitney U-test and Kruskal Wallis test were performed to calculate the difference between or among groups of data. A p value of less then 0.05 was considered as a statistically significant difference. 


\section{Results}

\section{Characteristics of subjects}

Table 1 depicted the characteristics of subjects. Most subjects were 2 year-old or more, female, and came from low socioeconomic status.

\section{Nutrient intakes in general}

The median intakes of macro and micronutrients were lower than RDA, ranged from 22\% (vitamin C) to $69 \%$ (phosphorus), except for vitamin A (406\%). The median intakes of calcium, calories, iron, thiamin, and protein were $23 \%, 30 \%, 37 \%$, $46 \%$, and $53 \%$ respectively. Out of 46 children, 26 experienced an improvement in nutritional status at the end of the study, whereas 20 did not. Table 2 shows a comparison between nutrient intakes among children with improvement in their nutritional status and those of children without any improvement. In general, the intakes were higher in the group of children with improvement except for vitamin A. However, Mann Whitney U-test was not able to detect any statistical significance $(\mathrm{p}>0.05)$.

\section{Nutrient intakes according to breastfeeding status}

In order to know the characteristics of nutrient intakes among children who experienced an improvement compared with those who did not, stratifications based on several variables were performed. Variables which were considered as confounders or effect modifiers were breastfeeding status and age of children. Table 3 shows that nutrient intakes among breastfed children who had improvement were higher than those who did not, except for vitamin A. However, these differences were not statistically significant (Mann Whitney U-test $p>0.05)$. The similar results can be seen in the group of non-breastfed children.

\section{Nutrient intakes according to age group}

Stratification using age showed that calories and thiamin intakes of older children ( 348 months were lower than those of younger children and these differences were statistically significant (Kruskal Wallis tests $\mathrm{p}=0.016$ and 0.022 respectively) (Table 4).

TABle 1. Characteristics of the CHILDREN

\begin{tabular}{llll}
\hline & Characteristics & $\mathbf{n}$ & $\%$ \\
\hline Sex & Boys & 18 & 39 \\
Age group & Girls & 28 & 61 \\
Number of child & $<2$ years & 17 & 37 \\
& $\geq 2$ years & 29 & 63 \\
Father's educational status & $1-2$ & 32 & 69 \\
& $3-4$ & 10 & 22 \\
& $>4$ & 4 & 9 \\
& Illiterate & 3 & 6 \\
& Primary school & 21 & 46 \\
Mother's educational status & Junior high school & 13 & 28 \\
& Senior high school & 7 & 15 \\
& Illiterate & 4 & 9 \\
& Primary school & 25 & 54 \\
Father's occupation & Junior high school & 10 & 22 \\
& Senior high school & 7 & 15 \\
& Labor & 17 & 37 \\
& Farmer & 12 & 26 \\
& Private employee & 3 & 6 \\
& Merchant & 2 & 4 \\
Mother's occupation & Jobless & 2 & 4 \\
& Others & 10 & 22 \\
& Housewife & 28 & 61 \\
& Farmer & 6 & 13 \\
& Labor & 5 & 11 \\
& Merchant & 1 & 2 \\
& Others & 6 & 13 \\
\hline
\end{tabular}

188 - Paediatrica Indonesiana, Vol. 43 No. 9-10 • September - October 2003 
Endy P Prawirohartono et al: Nutrient intakes in malnourished children during the economic crisis

TABLe 2. Nutrient INTAKES AMONG the ImPROVEMENT AND tHE NON-IMPROVEMENT GROUPS*

\begin{tabular}{llllllll}
\hline Nutrient & \multicolumn{3}{l}{ Improvement group* } & \multicolumn{4}{l}{ Non improvement group* } \\
& min & max & median & min & max & median & p $^{* *}$ \\
\hline Calories & 18 & 64 & 55 & 14 & 43 & 28 & 0.07 \\
Protein & 15 & 161 & 58 & 20 & 103 & 53 & 0.62 \\
Vitamin A & 9 & 2133 & 359 & 156 & 1111 & 420 & 0.72 \\
Thiamin & 17 & 98 & 56 & 24 & 76 & 43 & 0.11 \\
Vitamin C & 1 & 58 & 26 & 9 & 41 & 22 & 0.56 \\
Calcium & 5 & 89 & 23 & 12 & 66 & 23 & 0.71 \\
Iron & 5 & 80 & 39 & 19 & 81 & 37 & 0.72 \\
Phosphor & 13 & 187 & 70 & 27 & 139 & 68 & 0.98 \\
\hline
\end{tabular}

${ }^{*}$ All values were percentages of actual intakes/RDA

${ }^{* *}$ Analyzed using Mann Whitney U-test

Table 3. Median intakes among the Improvement AND the NON-IMPRovement GROUP OF the BREASTFED AND THE NON-BREASTFED GROUPS*

\begin{tabular}{|c|c|c|c|c|c|c|}
\hline \multirow[t]{2}{*}{ Nutrient } & \multicolumn{3}{|c|}{ Breastfed group } & \multicolumn{3}{|c|}{ Non-breastfed group } \\
\hline & Improvement & Non improvement & $p^{\star \star}$ & Improvement & Non improvement & $p^{\star *}$ \\
\hline Calories & 33 & 25 & 0.16 & 37 & 29 & 0.18 \\
\hline Protein & 59 & 41 & 0.16 & 58 & 55 & 0.94 \\
\hline Vitamin A & 316 & 513 & 0.48 & 413 & 420 & 0.91 \\
\hline Thiamin & 46 & 35 & 0.16 & 56 & 45 & 0.23 \\
\hline Vitamin C & 25 & 31 & 0.57 & 26 & 21 & 0.40 \\
\hline Calcium & 22 & 24 & 0.48 & 26 & 22 & 0.94 \\
\hline Iron & 34 & 29 & 0.40 & 42 & 41 & 0.37 \\
\hline Phosphor & 52 & 46 & 0.32 & 26 & 22 & 0.73 \\
\hline
\end{tabular}

* All values were percentages of actual intakes/RDA

${ }^{* *}$ Analyzed using Mann Whitney U-test

\section{Vitamin A intakes}

It was interesting, that vitamin $\mathrm{A}$ intakes in all children exceeded the RDA. We analyzed the feeding patterns of these children, especially the source of vitamin A in their diet. Vitamin A (retinal) is found in animal foods, such as liver, kidney, egg yolk, milk, and butter. However, vitamin A in the diet mainly comes from carotene, which is found in foods such as carrots, sweet potatoes, tomatoes, papaya, mango, orange, and dark leafy green vegetables including spinach. ${ }^{7,8}$ Based on the food records, generally children consumed foods that are rich in carotene such as spinach, tomatoes, carrots, papaya, egg, and sometimes milk and liver.

\section{Discussion}

In this study, $43 \%$ of children experienced improvement in their nutritional status, whereas the rest did not. We do not have any data explaining how the poor families fulfilled their food needs. However, all children in this study consumed lower intakes than the RDA, except for vitamin A. The vitamin A intake exceeded the RDA in all children. In this study, high dose vitamin A supplementations were not included in the calculations. Breast milk also was excluded from the calculations since there was not any valid method to calculate the amounts of nutrients in breast milk. The impact of economic crisis on nutrient intakes is clearly showed by survey data from 1995 to 1998 . Many households consumed less than $1500 \mathrm{kcal}$ and $32.2 \mathrm{~g}$ protein per capita per day or less than $70 \%$ of RDA. In urban areas, the prevalence of energy deficit at household levels increased from 49.45\% in 1995 to $51.10 \%$ in 1998 . The prevalence of protein deficit at household levels was 24\% in 1996 then increased in 1998. The mean intakes of vitamins and minerals showed similar figures. The mean intake of thiamin was only $50 \%$ of $\mathrm{RDA}$, whereas vitamin $\mathrm{C}$ was only $88 \%$ of RDA. Vitamin A showed a specific figure, because its mean intake exceeded the RDA. In 1998 the mean intake of vitamin A was $359.3 \%$ of RDA. The mean intakes of calcium, phosphorus, and iron showed the trend of decreasing from 1997 to 1998. The mean intake of calcium was only less than $50 \%$ of RDA, iron was $70 \%$ of RDA, while phosphorus 
Paediatrica Indonesiana

Table 4. Nutrient intakes according to age Group*

\begin{tabular}{|c|c|c|c|c|c|c|c|c|c|c|}
\hline \multirow[t]{2}{*}{ Nutrient } & \multicolumn{3}{|c|}{$<12$ months (6) } & \multicolumn{3}{|c|}{$12-47$ months (31) } & \multicolumn{3}{|c|}{$>48$ months (9) } & \multirow[t]{2}{*}{$\mathbf{p}^{\star \star}$} \\
\hline & $\min$ & $\max$ & median & $\min$ & $\max$ & median & $\min$ & $\max$ & median & \\
\hline Calories & 21 & 42 & 33 & 14 & 64 & 33 & 18 & 31 & 21 & $0.02^{* \star *}$ \\
\hline Protein & 37 & 110 & 71 & 15 & 161 & 54 & 24 & 67 & 39 & 0.05 \\
\hline Vitamin A & 73 & 1101 & 453 & 9 & 2133 & 333 & 156 & 603 & 425 & 0.96 \\
\hline Thiamin & 30 & 60 & 45 & 17 & 98 & 54 & 30 & 54 & 36 & $0.02^{\star \star \star}$ \\
\hline Vitamin C & 2 & 45 & 20 & 1 & 58 & 22 & 10 & 49 & 21 & 0.89 \\
\hline Calcium & 7 & 77 & 20 & 5 & 89 & 24 & 12 & 64 & 19 & 0.58 \\
\hline Iron & 10 & 70 & 39 & 5 & 81 & 42 & 29 & 80 & 37 & 0.87 \\
\hline Phosphor & 46 & 119 & 52 & 13 & 187 & 80 & 31 & 127 & 58 & 0.09 \\
\hline
\end{tabular}

* All values were percentages of actual intakes/RDA

** Analyzed using Kruskal Wallis test

*** Statistically significant

exceeded the RDA. ${ }^{2}$ These data came from 12 provinces in Indonesia, but it may be relevant with the situations in the study sites. In this study, almost all nutrient intakes were deficient, except for vitamin A. In line with the data surveyed from 12 provinces, the vitamin A intake was higher than that of the RDA. According to food records, children in this study consumed enough source of carotene such as green leafy vegetables and fruits, which are quite cheap in these areas.

There was a relationship between nutrient intakes and the improvement of nutritional status. Unfortunately, food supplementation in the two districts was stopped 2-8 months prior the beginning of this study. Therefore there was no contribution from this activity to the intakes of severe malnourished children. A study done in three provinces, Bali, West Kalimantan, and Lampung, showed a beneficial effect of food supplementation in preventing the degradation of nutritional status of the children. ${ }^{9}$ Other previous studies also demonstrated benefit of nutritional rehabilitation for children with moderate and severe malnutrition. Bredow et al reported the improvement of growth of the children after receiving a low cost, community-based treatment program at a health center. Management consisted of carefully delivered dietary advice, antibiotics, anthelminthics, and vitamin supplements. ${ }^{10}$ The sustainability of feeding program is necessary for the poor. A study done in Jamaica showed that the supplemented severely malnourished children gained significantly more weight than the non-supplemented children, but the advantage was lost once supplementation ceased. ${ }^{11}$ In this study, children with improvement consumed more calories and protein and other nutrients compared with those who did not experience any improvements. Among breastfed and non-breastfed group of children, the nutrient intakes influenced the improvement of nutritional status. These results show a role of fulfilling the nutrients for improving the nutritional status of severe malnourished children.

This study concluded that during the economic crisis the macro and micronutrient intakes of severely malnourished under five-year children were lower than those of the RDA, except for vitamin A. There were differences in nutrient intakes according to improvement in nutritional status and age group.

\section{References}

1. Kuswanto KR, Maksum M. The implication of the Asian financial crisis on Southeast Asia: The case of the food and agriculture sector of Indonesia. Proceedings of the $2^{\text {nd }}$ Regional Workshop on Food and Agricultural Policy; 1999 Aug 16-18; Bangkok, Thailand.

2. Latief D, Atmarita, Minarto, Jahari A, Tilden R. The trend of household food consumption before and during the crises in Indonesia. Widya Karya Nasional Pangan dan Gizi VII; 2000 Feb 29-March 2; Jakarta, Indonesia.

3. Kurniawan AI, Latief D. Childhood malnutrition in Indonesia, its current situation. Joint Symposium Between Department of Nutrition and Department of Pediatrics, Medical School, Sebelas Maret University and The Centre for Human Nutrition University of Sheffield UK; 2001 Feb 19-21; Surakarta, Indonesia.

4. Soekirman. The effect of economic crisis on the prevalence of childhood malnutrition in Indonesia. Proceedings of the Joint symposium between Department of Nutrition and Department of Pediatrics, Medical School, 
Paediatrica Indonesiana

Table 4. Nutrient intakes according to age Group*

\begin{tabular}{|c|c|c|c|c|c|c|c|c|c|c|}
\hline \multirow[t]{2}{*}{ Nutrient } & \multicolumn{3}{|c|}{$<12$ months (6) } & \multicolumn{3}{|c|}{$12-47$ months (31) } & \multicolumn{3}{|c|}{$>48$ months (9) } & \multirow[t]{2}{*}{$\mathbf{p}^{\star \star}$} \\
\hline & $\min$ & $\max$ & median & $\min$ & $\max$ & median & $\min$ & $\max$ & median & \\
\hline Calories & 21 & 42 & 33 & 14 & 64 & 33 & 18 & 31 & 21 & $0.02^{* \star *}$ \\
\hline Protein & 37 & 110 & 71 & 15 & 161 & 54 & 24 & 67 & 39 & 0.05 \\
\hline Vitamin A & 73 & 1101 & 453 & 9 & 2133 & 333 & 156 & 603 & 425 & 0.96 \\
\hline Thiamin & 30 & 60 & 45 & 17 & 98 & 54 & 30 & 54 & 36 & $0.02^{\star \star \star}$ \\
\hline Vitamin C & 2 & 45 & 20 & 1 & 58 & 22 & 10 & 49 & 21 & 0.89 \\
\hline Calcium & 7 & 77 & 20 & 5 & 89 & 24 & 12 & 64 & 19 & 0.58 \\
\hline Iron & 10 & 70 & 39 & 5 & 81 & 42 & 29 & 80 & 37 & 0.87 \\
\hline Phosphor & 46 & 119 & 52 & 13 & 187 & 80 & 31 & 127 & 58 & 0.09 \\
\hline
\end{tabular}

* All values were percentages of actual intakes/RDA

** Analyzed using Kruskal Wallis test

*** Statistically significant

exceeded the RDA. ${ }^{2}$ These data came from 12 provinces in Indonesia, but it may be relevant with the situations in the study sites. In this study, almost all nutrient intakes were deficient, except for vitamin A. In line with the data surveyed from 12 provinces, the vitamin A intake was higher than that of the RDA. According to food records, children in this study consumed enough source of carotene such as green leafy vegetables and fruits, which are quite cheap in these areas.

There was a relationship between nutrient intakes and the improvement of nutritional status. Unfortunately, food supplementation in the two districts was stopped 2-8 months prior the beginning of this study. Therefore there was no contribution from this activity to the intakes of severe malnourished children. A study done in three provinces, Bali, West Kalimantan, and Lampung, showed a beneficial effect of food supplementation in preventing the degradation of nutritional status of the children. ${ }^{9}$ Other previous studies also demonstrated benefit of nutritional rehabilitation for children with moderate and severe malnutrition. Bredow et al reported the improvement of growth of the children after receiving a low cost, community-based treatment program at a health center. Management consisted of carefully delivered dietary advice, antibiotics, anthelminthics, and vitamin supplements. ${ }^{10}$ The sustainability of feeding program is necessary for the poor. A study done in Jamaica showed that the supplemented severely malnourished children gained significantly more weight than the non-supplemented children, but the advantage was lost once supplementation ceased. ${ }^{11}$ In this study, children with improvement consumed more calories and protein and other nutrients compared with those who did not experience any improvements. Among breastfed and non-breastfed group of children, the nutrient intakes influenced the improvement of nutritional status. These results show a role of fulfilling the nutrients for improving the nutritional status of severe malnourished children.

This study concluded that during the economic crisis the macro and micronutrient intakes of severely malnourished under five-year children were lower than those of the RDA, except for vitamin A. There were differences in nutrient intakes according to improvement in nutritional status and age group.

\section{References}

1. Kuswanto KR, Maksum M. The implication of the Asian financial crisis on Southeast Asia: The case of the food and agriculture sector of Indonesia. Proceedings of the $2^{\text {nd }}$ Regional Workshop on Food and Agricultural Policy; 1999 Aug 16-18; Bangkok, Thailand.

2. Latief D, Atmarita, Minarto, Jahari A, Tilden R. The trend of household food consumption before and during the crises in Indonesia. Widya Karya Nasional Pangan dan Gizi VII; 2000 Feb 29-March 2; Jakarta, Indonesia.

3. Kurniawan AI, Latief D. Childhood malnutrition in Indonesia, its current situation. Joint Symposium Between Department of Nutrition and Department of Pediatrics, Medical School, Sebelas Maret University and The Centre for Human Nutrition University of Sheffield UK; 2001 Feb 19-21; Surakarta, Indonesia.

4. Soekirman. The effect of economic crisis on the prevalence of childhood malnutrition in Indonesia. Proceedings of the Joint symposium between Department of Nutrition and Department of Pediatrics, Medical School, 